\title{
The factors affecting team performance and ability to innovate in a globalised world
}

\author{
Slavka Silberg, ${ }^{1, *}$, Luděk Stehlík ${ }^{2,3}$, Michal Silberg ${ }^{4}$ and Rastislav Durišs \\ ${ }^{1}$ Constantine the Philosopher University in Nitra, Faculty of Education, Dražovská 4, 94901 Nitra, \\ Slovak Republic \\ ${ }^{2}$ Charles University in Prague, Faculty of Arts, Námestie J. Palacha 2, 11638 Praha, Czech Republic \\ ${ }^{3}$ Time is Ltd, s.r.o. Kafkova 14, 16000 Praha, Czech Republic \\ ${ }^{4}$ spoluHRame, s.r.o. Kmet'kova 5, 94901 Nitra, Slovak Republic
}

\begin{abstract}
Research background: Industry 4.0 and globalisation phenomena are rapidly changing the organisational environment and exert transformation pressure on organisations to be more agile and to keep up with global competition. These challenges create problems that require effective teamwork solutions. Hence, the need to identify potential barriers of effective team performance to sustain the competitive advantages through innovation.

Purpose of the article: The aim of this paper is to map the collaboration patterns and factors influencing teamwork and teams' ability to innovate and to measure their current level in the Slovak work teams.

Methods: The research of related studies and descriptive analysis of data from the TAS-II survey measures 8 key dimensions of team effectiveness (Context, Mission, Talent, Norms, Buy-in, Power, Morale, and Results) administered to the sample of 85 work teams from different economic sectors in the Slovak Republic between 12/2014 and 3/2021.

Findings \& Value added: Our research confirmed the importance of focusing on factors of team cooperation (e.g. right mix and quantity of talents, personally identify with mission, goals and metrics, empowerment, etc.). The so-called "Heartbeat analysis" of responses to 13 individual items from 3 TAS-II scales essential for effective team performance and ability to innovate (Mission, Talent, Power) indicated that 8 items had more "down" than "up" respondent votes. The most unfavourable were votes skewed in case of Mission-Metrics, Power-Budget, Talent-Number, Power-Authority and Power-Obstacles items in contrast to Mission-Purpose and TalentFollower items. We discuss the possible causes, advantages of team-based learning, necessity of systemic approach and the holistic view on teamwork.
\end{abstract}

Keywords: innovation management, organisation agility, team learning \& development, TAS-II.

JEL Classification: M19; M53; M54; J24;

\footnotetext{
* Corresponding author: slavka.silberg@,ukf.sk
} 


\section{Introduction}

Industry 4.0 and impact of globalisation is dynamically changing the organisational environment, increasing competition and creating opportunities to profit through innovation. Organisations revaluate and transform their technologies and processes to be more agile, accelerate innovation processes, nurture innovative culture, support proactive employees' behaviour to perform beyond the formal work requirements. Sarta et al. (2021) conceptualised the definition of organisational adaptation as the intentional, relational, conditioned and convergent attributes and also distinguishes the triggers and consequences between organisations and their environment. Innovation management and organisational agility enhance flexibility and resilience and are considered as the key drivers to seize an opportunity. Authors of the Emea survey (2019) emphasise that creativity, in the age of automation, is a crucial capability. In this regard, the soft skills expect and need by employees' are social skills, creativity, persuasion, collaboration, adaptability, and time management etc. Demand for creativity, higher cognitive and emotional skills will rise by 2030 (McKinsey, 2019). Organisational success continuity nowadays depends mainly on the teams' capability to develop innovative solutions (Jiang and Chen, 2018). New challenges generate the scope of problems that cannot be solved by one person alone, the need for enhancement of creativity, innovation and high-performance formed multidisciplinary and project-oriented transdisciplinary teams collaborating with stakeholders. Effective team cooperation and ability to learn belongs to the major competitive advantages. Studies confirm that innovative and high-performed teamwork seems to be more rare than common. McKinsey Global Innovation Survey (2019) confirm that Although 84\% of executives agree that innovation is important to growth strategy, only 6\% are satisfied with innovation performance and only a few exactly know what the problem is and how to improve. Very similar research results of Galpin (2020) confirmed the study.

The aim of this paper is to map the collaboration patterns and factors influencing teams' ability to innovate and measure the current level in the Slovak work teams. To know the status-quo enabled to effectively target actual needs, apply the right coaching and training approach to enhance the cognitive capital, to adapt faster, to foster the talent flow, to meet the expectations of stakeholders and to incentive and release creativity of employees. Our first goal is to analyse the data from related studies to find out the most important factors for workplace innovation and innovative work behaviour. The studies proved that the critical prerequisites for team performance and ability to innovate are innovation-supportive organisational culture (Klicheva and Klicheva, 2020), cognitive diversity (Zhongju and Siying, 2016; Kanchanabha and Badir, 2021), type of work, individual problem-solving styles of employees, perception of the psychological climate (Theurer et al., 2018), including degree of trust, psychological safety, relationships at workplace, leaders' personality and relationship to subordinates (Zalis et al. 2019) and leadership style (Jiang and Chen, 2018) etc. Transfer and knowledge sharing, job satisfaction, empowerment and intrinsic motivation are drivers of activity to deliver innovative outcomes (Malik, Sarwar and Orr, 2021) in a complex and highly demanding environment. Employees expect their job to fulfil individual self-determination, not oriented only on compensation and individual reward, but partnership, team's appreciation for their contribution. In addition, according to Klicheva and Klicheva (2020) the adequacy of resources may psychologically affect team members to realise and see the intrinsic value of the project and support innovation and creativity. They further note that teams with high vision and a clear mission are more likely to implement creative ideas than teams with unclear and vague or unconcrete missions, especially those have difficulties to develop further practical steps. To know the reason why to do something (e.g. necessity to innovate) and exactly define the teams' purpose, ranks Mission alongside with the situational context where teams' operate to the most important factors of teamwork. Institutional context and meaningfulness of work are crucial aspects of work engagement and 
performance to accomplish team goals (Curphy and Nilsen, 2019). The mission directly affects all the components of team work, it does not define the exact path to goal accomplishment, but from balancing empowerment through independence with convergence (Guest and Cole, 2020), creates and form shared understanding, provides that people feel connected, demonstrates positive social identity and attachment to the organisation. The followership is also related to the mission - without a clear communicated mission are discrepancies permanent risk, lack of involvement and commitment, mistrust and misconceptions among team members and the leader, and can make accomplishment of the goals impossible. According to Gest and Cole (2020), mission-based teams can more easily solve unpredictable situations and prioritise better than those who operates in traditional hierarchical business structures with very slow bureaucratic and rigid processes. The main aspect of an organisation's ability to innovate is their people in teams propelled by intrinsic motivation. It is confirmed that teams composed of divergent talents, typically maximise the potential of collaboration. Building high performing project-based teams composed of members from diverse educational background has a positive effect on innovative performance (Park, Jang, Smith and Thomas, 2020), and actively promotes experimenting with new ideas. Curphy and Nilsen (2019) further state that talent is more than just the number of people on the team, their reporting structure, the roles they fill, the degree to which they have a collective orientation and behave as good team players, and whether rewards are structured to promote teamwork and innovation. Due to talent shortcomings, many organisations do not realise their full innovation potential. Problems can occur because a team is too large, struggle for talent and diversity, or under individualists who are not real team players. Along with the impact of the style of leadership. The findings of Bak, Jin and McDonald survey (2021) proved that transformative leadership determined innovative behaviour of employees indirectly through psychological capital, might create or support a dependency on their leader. The study (Ruiz-Palomino and Zoghbi-Manrique de le Mara, 2021) proved that servant leadership and intrinsic motivation fuel creativity. The trend is to abandon managerial role fixation and transfer to a facilitator's role, map the needs and aspirations of the team, similarly, as by any other customer, apply a personalised leadership style, to be a "master integrator" (Lovric et al. 2018), to remove obstacles and hindering work barriers, facilitate and broaden the informal learning availability. Work teams are dynamic, diversified, adaptive, multidimensional, multifaceted social networks with their own culture, norms, history, creating evolving relationships in a social context (Park et al., 2020). A team's ability to adopt self-managing principles and create innovative outcomes strongly correlate together. The numerous studies (Lammers et al., 2016; Theurer et al., 2018) reflects the power aspiration of the sum of the employees and the job design independence and freedom positively affects individual job satisfaction, commitment and performance (e.g. creativity). The internal Citigroup, Inc. and LinkedIn Corp. survey (2014) confirmed that $64 \%$ of the respondents from employees would rather reduce their salaries by $10 \%$ in favour of more work flexibility. Theurer et al. (2018) study confirmed that all dimensions of autonomy (work scheduling, work methods, decision-making autonomy) has a significant positive effect on innovative employee's work behaviour. To succeed, foundational is to accept individual responsibility as the opportunity to make decision about themselves and over work in variety of situations and develop eligibility and the skills of assertive activation in shared leadership. Curphy and Nilsen (2019) state: ...the critical team resource is authority. Teams that are empowered to do what is needed in order to accomplish team goals are usually more successful than those that are micromanaged. Team empowerment also seems to be related to informal team learning, as those with enough authority better adapt to changing conditions than those tightly controlled. Yang, Liu and Gu (2017) proved that self-efficacy and power distance of leadership appreciably promotes team creativity. 


\section{Methodology}

The theoretical research of related studies and descriptive analysis of data from the TASII survey measuring 8 key interrelated components of team effectiveness (Context, Mission, Talent, Norms, Buy-in, Power, Morale, and Results) administered online to the opportunistic sample of 85 work teams from different economic sectors in the Slovak Republic collected between 12/2014 and 3/2021. The TAS-II questionnaire constructed by Curphy (Curphy and Hogan, 2012) is a complex tool for teamwork diagnostic and development. The psychometric qualities of Slovak localisation were partially tested by Stehlík (2019, not published) with reliability of McDonald's omega scales $(\omega)$ varied from .72 to .87 and factor validity $R M S E A$ $=0.033, C F I=.934, T L I=.928$.

Table 1. Participants' Team roles.

\begin{tabular}{|c|c|c|}
\hline $\begin{array}{c}\text { Participant role } \\
<\mathbf{f c t}>\end{array}$ & $\begin{array}{c}\text { Count } \\
<\text { int }>\end{array}$ & $\begin{array}{c}\text { Proportion (\%) } \\
<\mathbf{d b l}>\end{array}$ \\
\hline Others & 9 & 1.1 \\
\hline Team Leader & 75 & 9.0 \\
\hline Team Member & 740 & 88.6 \\
\hline Team Supervisor & 11 & 1.3 \\
\hline
\end{tabular}

Source: authors (2021)

Table 2. Size of teams.

\begin{tabular}{|c|c|c|c|c|c|c|c|}
\hline & $\begin{array}{c}\text { Mean } \\
<\mathbf{d b l}>\end{array}$ & $\begin{array}{c}\text { SD } \\
<\mathbf{d b l}>\end{array}$ & $\begin{array}{c}\text { Q1 } \\
<\mathbf{d b l}>\end{array}$ & $\begin{array}{c}\text { Median } \\
<\text { int }>\end{array}$ & $\begin{array}{c}\text { Q3 } \\
<\mathbf{d b l}>\end{array}$ & $\begin{array}{c}\text { Min } \\
<\text { int }>\end{array}$ & $\begin{array}{c}\text { Max } \\
<\text { int }>\end{array}$ \\
\hline $\begin{array}{c}\text { Size of } \\
\text { teams }\end{array}$ & 9.82 & 4.58 & 6 & 9 & 13 & 3 & 25 \\
\hline
\end{tabular}

Source: authors (2021)

\section{Results}

The purpose of this study was to map the collaboration patterns and factors influencing teamwork and workplace innovation and measure their current level in the Slovak Republic. The first goal to explore and investigate, the essential factors affecting team ability to innovate, was achieved in the theoretical part. The research of related literature confirmed the importance of focusing on customer needs saturation, organisational culture, factors of team cooperation (right mix structure and quantity of talents, identification with mission, goals and metrics, empowerment in decision making and to take a certain risk to overcoming obstacles etc.), significantly correlates with a team's ability to innovate. The second goal of the study cohere and fluently connects to the results described in the theoretical part. Due to the convincing correlation and causation with teams' ability to innovate supported by previous research, we focused on Mission, Power and Talent items of TAS-II. The following basic descriptive statistics were conducted only with datapoints coming from participants with the Team Member role, because their perception of teamwork effectiveness influence the innovation performance and the teams' ability to innovate. Respondents chose one option that best aligns with their view on 5-point Likert scale (ranging from 1 - strongly disagree to 5 - strongly agree). 
Table 3. Descriptive statistics of scores on 3 TAS-II scales that are relevant for teams' ability to innovate.

\begin{tabular}{|c|c|c|c|c|c|c|c|c|c|c|c|c|}
\hline $\begin{array}{l}\text { Scale } \\
\text { <fct }>\end{array}$ & $\begin{array}{r}n \\
<i n t>\end{array}$ & $\begin{array}{r}\text { Missing } \\
<\text { int> }\end{array}$ & $\begin{array}{l}\text { Mean } \\
<\mathrm{db} \mid>\end{array}$ & $\begin{array}{r}\text { SD } \\
<\mathrm{db} \mid>\end{array}$ & $\begin{array}{r}\text { SE } \\
<\mathrm{dbl}>\end{array}$ & $\begin{array}{r}\text { Q1 } \\
<\mathrm{db} \mid>\end{array}$ & $\begin{array}{r}\text { Median } \\
<\mathrm{db}>\end{array}$ & $\begin{array}{r}\text { Q3 } \\
<\mathrm{db} \mid>\end{array}$ & $\begin{array}{r}\text { Skewness } \\
<\mathrm{dbl}>\end{array}$ & $\begin{array}{r}\text { Kurtosis } \\
<\mathrm{dbl}>\end{array}$ & $\begin{array}{r}\text { Min } \\
<\mathrm{dbl}>\end{array}$ & $\begin{array}{l}\text { Max } \\
<\mathrm{db}>\end{array}$ \\
\hline Mission & 740 & 2 & 3.76 & 0.81 & 0.030 & 3.25 & 3.75 & 4.25 & -0.61 & 3.19 & 1 & 5 \\
\hline Talent & 740 & 2 & 3.79 & 0.71 & 0.026 & 3.40 & 3.80 & 4.20 & -0.51 & 3.17 & 1 & 5 \\
\hline Power & 740 & 7 & 3.59 & 0.70 & 0.026 & 3.00 & 3.75 & 4.00 & -0.39 & 3.15 & 1 & 5 \\
\hline
\end{tabular}

Source: authors (2021)

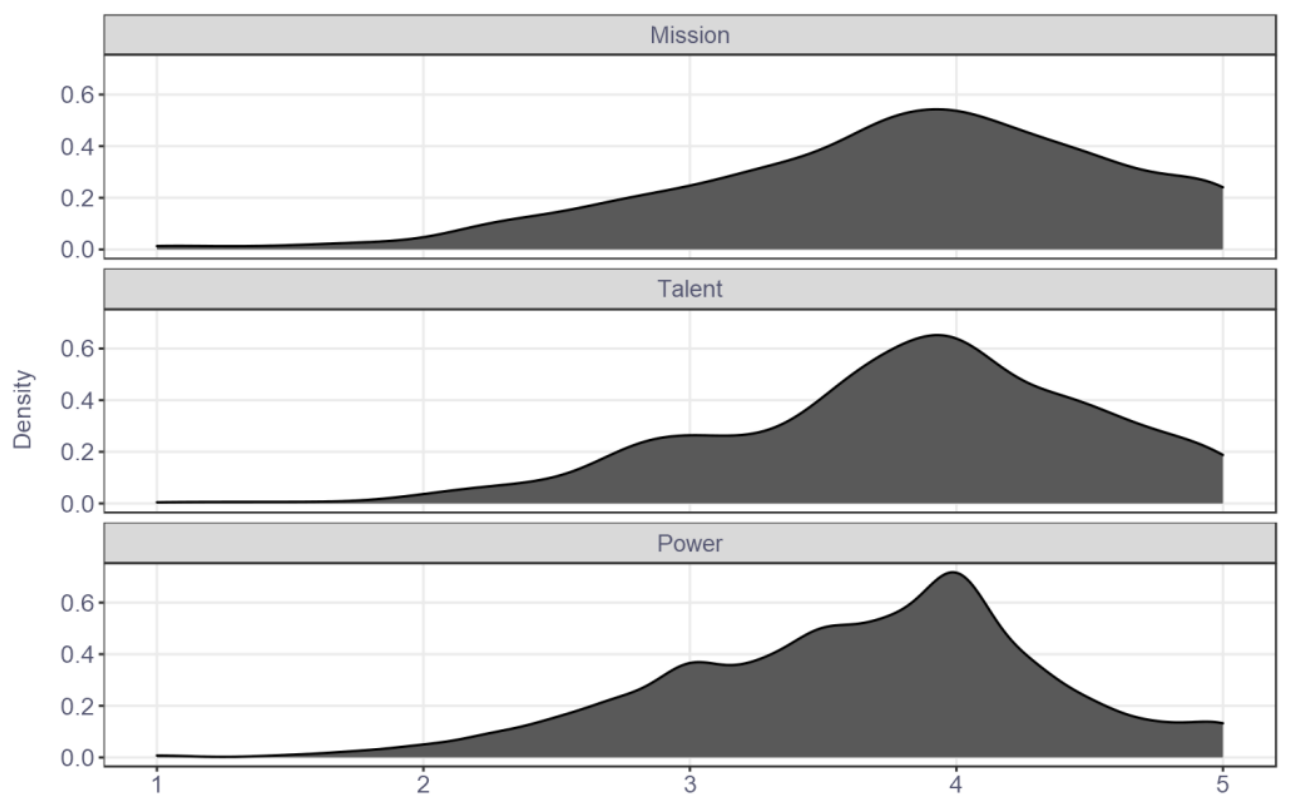

Figure 1. Distribution of scores on TAS-II scales that are most relevant for teams' ability to innovate.

Source: authors (2021)

Although the results indicate that the situation in the research sample is generally positive and at first glance, acceptable (see the graphs in Fig. 2 - 4 with distribution of un/favourable and neutral responses to individual items), the "Heartbeat analysis" of responses to individual Mission, Talent and Power scale items that take into account the fact that participants differ in the central tendency of their responses is confirmed by unfavourable votes in some items. The "Heartbeat analysis" counts respondents' "Up" and "Down" votes and it computes them in the following way: the average response and standard deviation of responses are computed for each participant, then participants' responses are transformed to z-scores, and if greater or smaller than 1 or -1 , respectively, the response is counted as "Up" or "Down" vote, respectively. The most unfavourable were votes skewed in case of Metrics (scale Mission), Budget (scale Power), Number (scale Talent), Authority (scale Power) and Obstacles (scale Power) items in contrast to the Purpose (scale Mission) and Follower (scale Talent) items. 


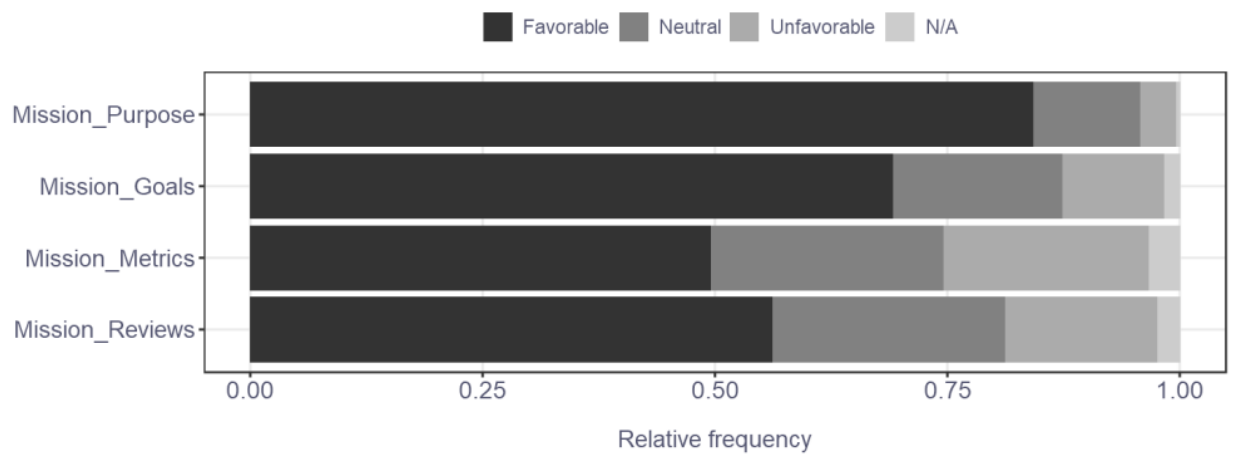

Figure 2. Distribution of responses to individual Mission scale items.

Source: authors (2021)

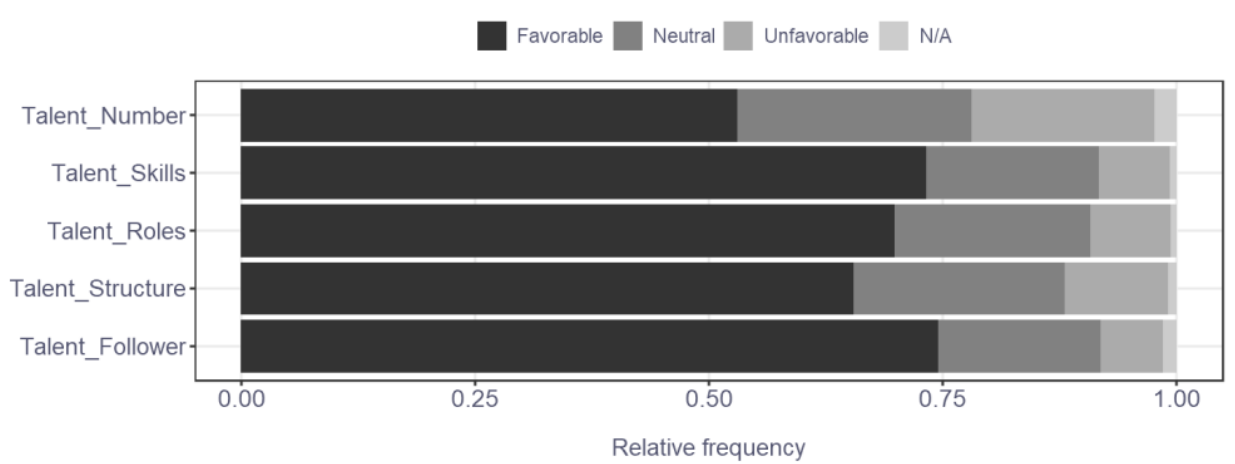

Figure 3. Distribution of responses to individual Talent scale items.

Source: authors (2021)

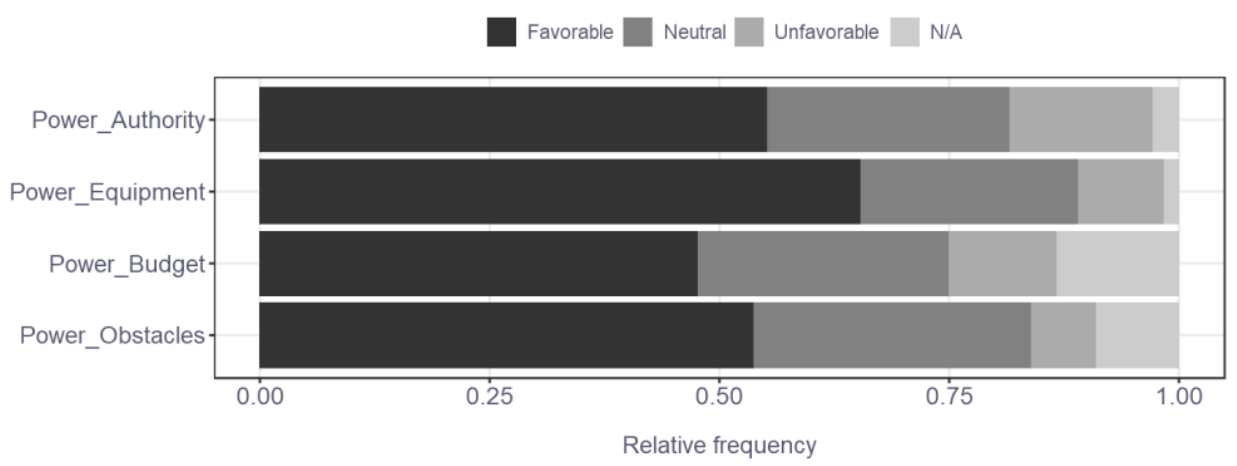

Figure 4. Distribution of responses to individual Power scale items.

Source: authors (2021)

The visualisation of favourable, neutral and unfavourable responses to individual Mission, Talent and Power scale items are defined below as favourable 4 - 5 responses, 3 as neutral and $1-2$ responses as unfavourable. 
Table 4. Proportion of "Up" and "Down" votes for individual items in the selected scales (Mission, Talent, Power).

\begin{tabular}{|c|c|c|c|c|c|}
\hline Items & Down & Up & $\begin{array}{c}\text { Proportion of } \\
\text { Down votes }\end{array}$ & $\begin{array}{c}\text { Proportion of } \\
\text { Up votes }\end{array}$ & nVotes \\
\hline Mission_Metrics & 270 & 72 & 0.79 & 0.21 & 342 \\
\hline Power_Budget & 205 & 56 & 0.79 & 0.21 & 261 \\
\hline Talent_Number & 258 & 72 & 0.78 & 0.22 & 330 \\
\hline Power_Authority & 214 & 61 & 0.78 & 0.22 & 275 \\
\hline Power_Obstacles & 133 & 39 & 0.77 & 0.23 & 172 \\
\hline Mission_Reviews & 185 & 86 & 0.68 & 0.32 & 271 \\
\hline Power_Equipment & 149 & 76 & 0.66 & 0.34 & 225 \\
\hline Talent_Structure & 117 & 81 & 0.59 & 0.41 & 198 \\
\hline Talent_Roles & 109 & 119 & 0.48 & 0.52 & 228 \\
\hline Mission_Goals & 111 & 129 & 0.46 & 0.54 & 240 \\
\hline Talent_Skills & 96 & 123 & 0.44 & 0.56 & 210 \\
\hline Talent_Follower & 86 & 164 & 0.34 & 0.66 & 250 \\
\hline Mission_Purpose & 29 & 212 & 0.12 & 0.88 & 241 \\
\hline
\end{tabular}

Source: authors (2021)

\section{Discussion}

The focus on dynamic interplay of all team components to optimise performance and maximise innovation gaining momentum in a globalised world. Our data support that most problems and opportunities for improvement are related to the system (management) and revealed that the most unfavourable votes are skewed in case of Mission-Metrics, PowerBudget, Talent-Number, Power-Authority and Power-Obstacles items in contrast to the Mission-Purpose and Talent-Follower items. The respondents' votes in Mission scale confirmed that, except for the case of Metrics item respondents are satisfied with the condition of Mission components (e.g. purpose of the team, team goals). Apparent, the lack of the Metrics item rating in Mission scale means that teams do not have regular evaluating criteria and information about their progress, knowledge about the current level of team goals compared to their strategic plans. If the performance measurements or benchmarks for comparison of distinction between teams is missing, it may lead to stagnation, resignation and complacency with results. Moreover, many team members feel less comfortable with Talent-Number item perception, which include acquisition of talents, retaining, etc. Studies have shown different results. Communication lines in teams were studied also by Brooks (1995 p. 25), who observed and simplified that adding manpower to a project that is late makes it even later (similarly, the Ringelmann effect - that sometimes less is more). We agree with this statement partially, fundamentally it is correct to identify the diverse set of eligibility, experience of team members, circumstances and situational context to build the team with accurate staff quantity. This deficiency is often caused by insufficient dialogue, roles assignation, communication channels and network. It is effective when the team selects new members to fit into the team. This is supported by the empirical evidence of Kanchanabha and Badir (2021) that teams' cognitive diversity, network density and sustain dynamic cohesion (Lovric et al., 2018; Park et al., 2020) beneficially influence innovation capability. Not only talents, but also empowerment to decide, as well is particularly motivational and this facilitates the ability to create new innovative solutions. The PowerAuthority item results confirmed the need of employees for a prompt decision, as the 
constructive modifications are variable. Further, hierarchical structure and very tight control of command are often bound creativity, dampen job satisfaction and joy from work. We identify with Lammers et al. (2016) opinion, that most people do not aspire for power to rule over others, but only autonomy to control their own domain. This corresponds with several studies. Advocates of a verified more pervasive agile approach, consider these areas highly important to shift competences on to teams, support their self-confidence, common commitment, engagement and intrinsic motivation through distributed or shared leadership. Power-Budget item evidently shows deficiency in team members perception of resources adequacy. Teams' assets are oft more likely sufficient than not, but they are used ineffectively. Teams often do have insufficient information on compliance with the budget neither involved in budgeting process etc. A reasonable targeted long-term investment approach, as well as achieving the team mission and fulfilling the desired outcomes with the set of resources is certainly needed (Guest and Cole, 2020). For real innovation breakthrough, it is not as important how many resources we have at our disposal, as the actions we take daily to move things forward (e.g. creative self-efficacy and imagination, self-discipline, the way of thinking). Related this to more "Down" votes in the Power-Obstacles item indicates that teams do not feel confident enough or empowered to remove obstacles. To adapt faster, to think in context and to act agile, to enhance individual confidence and creativity is a verified way the team-based training (in team preferred form and style), to put emphasise on sharing the different perspectives and tacit knowledge to their peers. Many of the earlier publications focused on building trust in team as a predictor of effective team cooperation. It is also beneficial to build faster reactions, situational awareness, mindfulness, to improve team performance, to tighten team cohesion, cooperate and build relationships with stakeholders. Agility, openness to change and ability to innovate can be influenced by training, like other skills. Several studies (Saha et al, 2020) have proved the advantages of organisational and team-based learning and organisational agility to accelerate the level of creativity and competency. It helps to recognise and unleash talents, the joy of learning, experimenting, easier upskilling and reskilling, support mutual trust, open communication and critical thinking on the way to innovation and expertise. It is needed to decentralise and liberate the current structures toward taking responsibility by team members. The full control is impossible. We see an organisational opportunity to evolve and delegate the part of decision-making powers, because positive peer-pressure, intrinsic motivation and driven are much stronger than hierarchical forces. Organisations should utilise this advantage and focus on effective communication, feedback (both positive or negative), teamwork and invest in team cross-training in underperformed areas. People prefer to be happy at work, proud of their jobs, so they have to know the reason why their contribution is a valued asset for others. The possibility to speak up freely without concern for compromising one's own reputation can trigger valued feedback from employees, as well as promote preferred abilities and attitudes. Adaptation and direction correction on external changes via continual team learning process, is the tool how to handle with uncertainty and also leads to organisational creativity (Jeong and Shin, 2017; Saha et al., 2020). The biggest innovation obstacles include the rigorous old way of thinking and underestimation of communication and alertness. Even small adopted changes towards a team's autonomy and empowerment can be beneficial and impact it's performance along with tailored team training can unlock creative potential across an organisation and close the skills gap. These changes depend on mutual communication and regular feedback, and companies modifying their attitude towards employees - treat them like stakeholders. Such an approach can contribute to job satisfaction, co-ownership, unleash the hidden potential and kick-start organisational change that boosts creativity, create a longterm competitive edge to thrive over time. 


\section{Conclusion}

Creativity can be viewed and generalised as the attribute of every person and belongs to fundamental human nature. Contemporary organisations are looking for the right mix of team members' attitudes, abilities and skills to increase the whole individual engagement and improve the team performance to find extraordinary solution and outcomes. Our research study maps the collaborations pattern and factors influencing teams' ability to innovate. In a globalisation context, it is a highly relevant theme, because organisations can survive, succeed and prosper only thanks to the innovation-driven progress of a joint team effort in a larger market scope than their competitors. The study confirmed the importance of focusing on the key factors of team cooperation, ultimately enhancing the ability to innovate. We suggest that the innovation process, from ideation to implementation, to valuable output for stakeholders, requires a new approach i.e. to avoid micromanagement, shift decision-making powers and responsibilities to work teams and enhance team-learning. Globalisation and Industry 4.0 are chances by taking capitalise advantage to innovate. The key is to focus attention on teamwork effectiveness, predominantly to foster creativity and job satisfaction of employees by team-based learning to spark original thinking. Our study has several contributions. Firstly, the research findings bring new insight on teamwork aspects which affects teams' creativity. Secondly, conclusions can be valuable for the theory and meaningful implications for the practice of personnel management, professional andragogy and organisational psychology, or may be an inspiration for further organisational research, respectively. The study also highlights the learning culture evolvement, trust-based team learning to scale-up the high-priority characteristics i.e. agility, resistance, job happiness and satisfaction, creativity. It points out the importance of using regularly measurement tools in practise of any professional HR specialists, enable a deeper view and evaluation of current team cooperation level and pave the way. Limitations of the study: Because of opportunistic data sampling and an unrepresentative research sample, the results cannot be generalised. Further research on a larger sample is needed.

\section{Acknowledgements}

This work was supported by the Scientific Grant KEGA reg. No. 005/UKF-4/2021 "The social skills development of educands in tertiary and further education" and UGA reg. No. V9/2021 "Selected aspects of teamwork with an impact on job satisfaction and engagement of employees and the possibilities of their transformation through a training program utilising the agile approach".

\section{References}

1. Bak, H., Jin, M. H., \& McDonald, B. D. (2021). Unpacking the transformational leadership -Innovative work behaviour relationship: The mediating role of psychological capital. Public performance \& Management review. https://doi.org/10.1080/15309576.2021.1939737

2. Brooks, F. P. (1995). The mythical man-month: The essays on software eingineering. Anniversary edition. Eddison-Wesley.

3. Curphy, G. J., \& Hogan, R. (2012) The Rocket Model: Practical Advice for Building High Performing Teams. Tulsa: Hogan Press.

4. Curphy, G. J., \& Nilsen, D. (2019). The Rocket Model: A Roadmap to Building High Performing Teams. North Oaks, MN: Curphy Leadership Solutions. 
5. Galpin, T. (2020). Nudging innovation across the firm - aligning culture with strategy. Journal of business strategy. https://doi.org/10.1108/JBS-07-2020-0147

6. Guest, M., \& Cole, J. (2020). Mission-base teams: Reconstructing business as an evolving network as teams and outcome. Deloitte.

7. Jeong, J., \& Shin, S. J. (2017). High performance work practices and organizational creativity during organizational change: A collective learning perspective. Journal of Management. 20(10). 1 - 17.

8. Jiang, Y., \& Chen, C. C. (2018). Integrating knowledge activities for team innovation: Effect of transformational leadership. Journal of Management, 44, 1819 - 1847.

9. Kanchanabha, B., \& Badir, Y. F. (2021). Top management Team's cognitive diversity and the Firm's ambidextrous innovation capability: The mediating role of ambivalent interpretation. Technology in Society 64.

10. Klicheva, K., \& Klicheva, G. (2020). Team creativity and innovation: psychological factors affecting organizational bahavior. European Journal of research and reflection in educational sciences. 8(12). 115 - 119.

11. Lammers, J., Stoker, J. I. Rink, F., \& Galinsky, A. D. (2016). To have control over or to be free from others? The desire for power reflects a need for autonomy. Personality and social psychology bulletin. 42(4). 498 - 512.

12. Lovric, D., Canner, N., \& Warner, C. (2018). Ignition teams: Rising to the challenges of innovation. People + Strategy 41(2).

13. LinkedIn Talent solutions. (2019). Global talent trends: The 3 trends transforming your workplace. https://business.linkedin.com/content/dam/me/business/en-us/talentsolutions/resources/pdfs/global_talent_trends_2019_emea.pdf

14. Malik, M., Sarwar, S., \& Orr, S. (2021). Agile practises and performance: Examining the role of psychological empowerment. International Journal of Project Management $39,10-20$.

15. McKinsey \& Company. (2019). Globalization in transition: The future of trade and value chains.

https://www.mckinsey.com/ /media/mckinsey/featured\%20insights/innovation/globali zation $\% 20$ in $\% 20$ transition $\% 20$ the $\% 20$ future $\% 20$ of $\% 20$ trade $\% 20$ and $\% 20$ value $\% 20$ cha ins/mgi-globalization $\% 20 \mathrm{in} \% 20$ transition-the-future-of-trade-and-value-chains-fullreport.pdf

16. McKinsey. (2019). Growth and innovation. https://www.mckinsey.com/businessfunctions/strategy-and-corporate-finance/how-we-help-clients/growth-and-innovation

17. Park, S., Grosser, T. J., Roebuck, A. A., \& Mathieu, J. E. (2020). Understanding work teams from a network perspective: A review and future research direction. Journal of management. 44(6), $1002-1028$.

18. Park, N. K., Jang, W., Smith, J., \& Thomas, E. L. (2020). How to organize creative and innovative teams: creative self-efficacy and innovative team performance. Creative research journal 33 (1), 1 - 12.

19. Saha, N., Sáha, T., Gregar, A., \& Sáha, P. (2020). Organizational Agility and organizational learning: Do they accelerate organizational innovation and competency? European conference on innovation and entrepreneurship. DOI: 10.34190/EIE.20.030

20. Sarta, A., Durand, R., \& Vergne, J. P. (2021). Organizational adaptation. Journal of Management. 47(1), 43 - 75, DOI: 10.1177/0149206320929088

21. Theurer, C. P., Tumasjan, A., \& Welpe, I. M. (2018). Contextual work design and employee innovative work bahavior: When does autonomy matter? PLOS ONE 13(10). 
22. Ruiz-Palomino, P., \& Zoghbi-Manrique de Lara, P. (2021). How and when servant leaders fuel creativity: The role of servant attitude and intrinsic motivation. International Journal of Hospitality Management. DOI: 10.1016/j.ijhm.2020.102537

23. Yang, J., Liu, H., \& Gu, J. (2017). A multi-level study of servant leadership on creativity: The roles of self-efficacy and power distance. Leadership and Organization development journal, 38 (5), 610 - 629.

24. Zalis, L, Procházka, J., \& Vaculík, M. (2019). Mind the Silver Bullet Thinking: A Multilevel Study on the Impact of Manager Trait Mindfulness on Subordinate Objective Job Performance. Front. Psychol. 10:2171. DOI: 10.3389/fpsyg.2019.02171

25. Zhongju, L., \& Siying, L. (2016). Cognitive Diversity, Alertness, and Team Performance. Social Behavior and Personality: an international Journal, Vol. 44, (2) 209 - 220. Scientific Journal Publishers. https://doi.org/10.2224/sbp.2016.44.2.209 